\title{
A FURTHER CONTRIBUTION TO THE QUESTION OF TURPENTINE SUBSTITUTES.
}

\author{
By J. H. COSTE, F.I.C., AND L. MYDDELTON NASH, F.I.C.
}

(Read at the Meeting, April 5, 1911.)

There is abundant evidence of the presence of cyclic hydrocarbons (benzene and its homologues) in greater or less amount in petroleum from almost all sources. * In some varieties the proportion is very considerable. The examination by one of us of several materials sold as turpentine substitutes showed that these substances contained large percentages of such hydrocarbons, in addition to the more commonly recognised paraffins or cyclo-paraffins (ANALYST, 1910, 35, 438). The limiting effect of aromatic hydrocarbons on the process proposed by F. W. Richardson and J. L. Bowen (J. Soc. Chem. Ind., 1908, 27, 613) was indicated, and the intelligent application of Armstrong's method of polymerisation was advocated. It was shown that diluted sulphuric acid of the strength recommended by that author ( $J$. Soc. Chem. Ind., 1882, 1, 480) had but little action on the turpentine substitutes then examined.

Richardson and J. E. F. Whitaker (J. Soc. Chem. Ind., 1911, 30, 115), in a later paper, agree with us that certain petroleums contain very appreciable amounts of benzene homologues, but apparently consider that only in Borneo petroleum is their amount worth taking into account. They state that the products of American petroleum are by far the most extensively used for adulterating turpentine, that for a year no Borneo spirit has been imported into Europe, and that they have never met with any turpentine substitute or turpentine adulterant composed of Borneo spirit.

In our experience, based on a knowledge of the materials in the London market, Roumanian spirit is by far the most extensively used for this purpose, although some American and Borneo spirit is also used. The reason is that the yield of "spirit" is greater (in the proportion of about $7: 4$ ) from Roumanian petroleum than from American, which, on the other hand, yields a better burning oil.

There is on the market a large quantity of pure Borneo spirit which is suitable for, and is used as, a turpentine substitute or adulterant. About 5,000 tons a year are imported, of which some 3,000 tons are used for this purpose. It is true, however, that no Borneo crude oil has been imported recently, as it is now distilled on the spot. The Borneo oil and spirit now being obtained are entirely different from that obtained a few years ago, the wells being sunk very much deeper and yielding a much lighter oil.

We agree that petroleum spirit, and not crude petroleum (by which is probably meant burning oil, crude petroleum being a thick brown liquid), is used to adulterate turpentine. The burning oil is not nearly sufficiently volatile for the purpose. American petroleum (burning oil) on distillation would only yield 90 per cent. at

* Steuart ( $J$. Soc, Chem. Ind., 1900, 19, 989) Poni (ibid., 1906, 25, 214 ; 1907, 26, 958). Zaloziecki and Hausmann (ibid, 1907, 26, 1132). Edeleanu (ibid., 1908, 27, 438). Jones and Wootton (J. Chem. Soc., 1907, 91, 1146). 
about $330^{\circ} \mathrm{C}$; ; whereas the petroleum spirit suitable for turpentine substitute would yield 90 per cent. at about $210^{\circ} \mathrm{C}$, and an ordinary good turpentine substitute will yield 95 per cent. at about $210^{\circ} \mathrm{C}$, and, in the case of Borneo spirit at a somewhat lower temperature.

Benzene, which is mentioned as a possible adulterant, should be out of the question, on account of its inflammability. Turpentine containing even 10 per cent. of benzene inflames at the ordinary temperature, and serious trouble with insurance companies and carriers would arise, to say nothing of the danger of making and using varnishes and paints with such spirit. For the same reason "gasolene," which Richardson and Whitaker also mention, and with which they have made various experiments, is an equally improbable adulterant. It is unlikely that spirit flashing below $73^{\circ} \mathrm{F}$. is used for this purpose.

Richardson and Whitaker apparently realise that the use of a physical method of analysis is only possible in very restricted cases, when the nature of the constituents is accurately known and their amounts only are in doubt. They have supplemented the original method, which was probably sound in the simple case assumed by them by a chemical one which is certainly useful. They determine the "barium sulphate coefficient," which is a measure of the amount of sulphonation occurring when the liquid is treated with sulphuric acid under certain definite conditions. Their figures seem to show that under these conditions the sulphonation (of benzene) is not complete, as the amount of barium sulphate obtained is less even than that required for toluene. Experiments with Borneo and American petroleum and with American turpentine, which are quoted by them, show that whereas Borneo oil contains a large amount of constituents which can be sulphonated, American oil contains less, but still a notable amount, as does American turpentine (cymene, probably, formed by the action of the acid itself).

As no considerable amount of constituents boiling below $140^{\circ} \mathrm{F}$. has been found by us, the presence of benzene or toluene is, apart from the commercial considerations already set forth, improbable in turpentine substitutes or adulterants, and, in our opinion, it is not desirable to return either of these hydrocarbons as present without direct proof of their presence. For these reasons we cannot consider the examples given by Richardson and Whitaker of analyses of mixtures containing benzene as in any way representing those likely to occur* in practice, nor do we think that with unknown constituents it would be possible to return analyses in the form given by them-i.e., as percentages of turpentine, petroleum, gasolene, and benzene-but only as terpenes, homologues of benzene, and paraffins and cyclo-paraffins.

The separation from turpentine by fractional distillation of any adulterant likely to be employed is highly improbable of accomplishment, if not absolutely impossible.

In all cases where a sample of turpentine is suspected, its " close flash" (Abel test) should be taken. This figure for the pure article has not been found in the authors' experience to vary more than a few degrees, and all samples which they have examined have a close flash of $90^{\circ}$ to $94^{\circ} \mathrm{F}$. Any departure from these figures will make it necessary to examine the turpentine very closely. The simplest method,

* We use advisedly the expression "likely to occur," since neither of us has for some years found an adulterated sample of turpentine. 
however, to determine whether or not the sample is pure is simply to shake it, when any froth will indicate that the turpentine is impure, and suggest the presence of petroleum adulterants (Nash, ANaLYst, 1908, 33, $231 ; 1909,34,151$ ). Coal-tar benzene does not give any froth, but, as previously stated, this could not be used.

Distillation of the sample will also give valuable information, as most turpentine substitutes and adulterants show a considerable rise in temperature towards the end of the distillation. Old and oxidised turpentine may also show a considerable rise, on account of the large amount of "residue" contained. A difference of as much as $13^{\circ} \mathrm{C}$. has been noticed by one of us in the temperature at which the 95 per cent. fraction distilled in the case of two samples taken from bulk-deliveries of genuine American turpentine-the residue being respectively 4 per cent. and 1.9 per cent. An examination of the residue will show at once whether the rise was caused by petroleum spirit or by oxidation of the turpentine. We give the results of the examination of a few samples of turpentine substitutes obtained recently, which appear to be of special interest.

TABLe I.

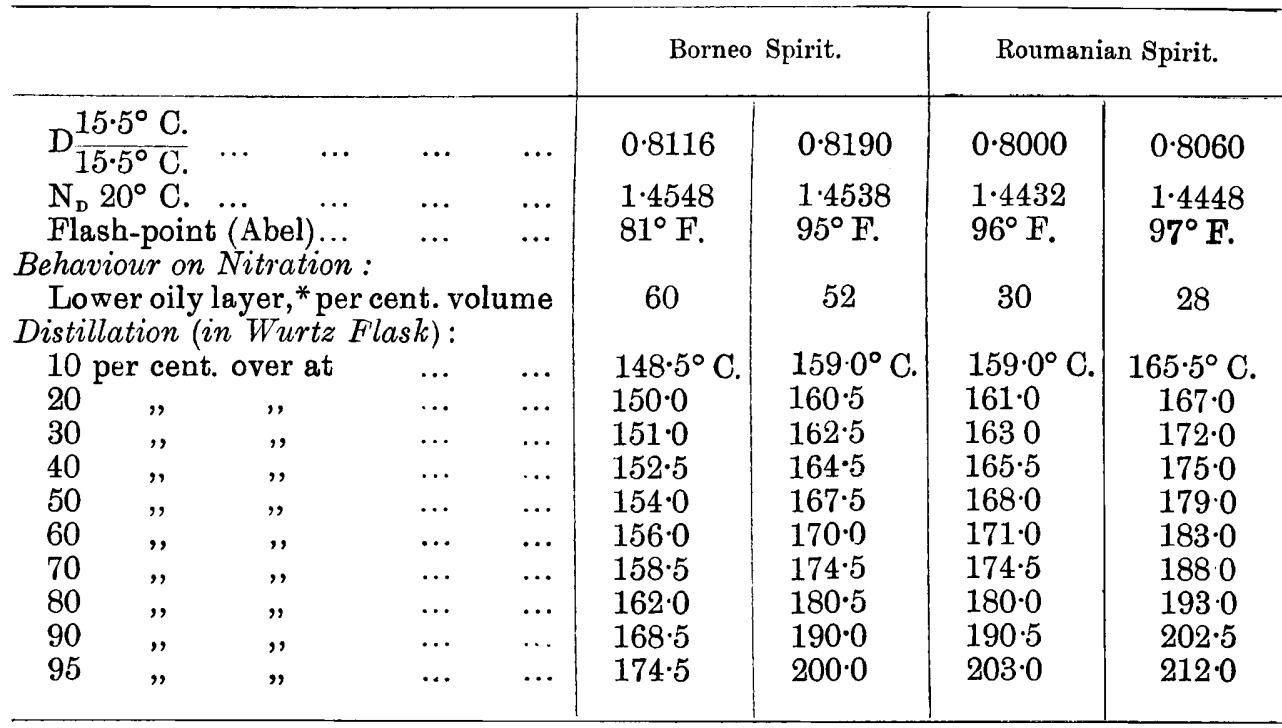

These are typical of the materials now in common use as turpentine substitutes, and in physical and chemical properties are similar to other earlier samples examined by us (Coste, ANaLYst, loc. cit.), and to several recently obtained from ordinary trade sources. They are obviously mixtures of aromatic and aliphatic hydrocarbons containing considerable proportions of the former class of bodies. It has been shown that such mixtures are very little acted on by diluted sulphuric acid of the strengths recommended by Armstrong; and as it appeared desirable to make certain that this behaviour was not affected by the presence of terpenes, the following series of experiments was made.

\footnotetext{
* This is an approximate indication of the amount of aromatic hydrocarbons.
} 
Measured quantities (from 100 to 200 c.c.) of mixtures of American turpentine and turpentine substitutes, such as are actually used, were treated with the diluted acids used by Armstrong for polymerisation, the treatment with the stronger acid being repeated as advised by him. The modification suggested by Morrell $(J$. Soc. Chem. Ind., 1910, 29, 241) was adopted, but in view of the probable presence of aromatic hydrocarbons treatment with strong acid was omitted, it being sought to confine the action to one of polymerisation. The results are given in Table II.

It was found in 1910 that the average loss suffered by turpentine substitutes when treated as above was 3 per cent. Armstrong states that about 5 per cent. of unpolymerisable liquid is left by pure American turpentine. If desired, the percentages of terpenes and of other hydrocarbons found can be corrected for these amounts. We give these corrected results in the third column. The correction is naturally less accurate when the proportion of either constituent is very small.

TABLE II.

\begin{tabular}{c|c|c|c}
\hline & $\begin{array}{c}\text { Volume Percentage of } \\
\text { Adulterant. }\end{array}$ & $\begin{array}{c}\text { Volume Percentage of } \\
\text { Unpolymerised Distillate. }\end{array}$ & $\begin{array}{c}\text { Corrected Volume Per- } \\
\text { centage of Adulterant. }\end{array}$ \\
\hline II. & 35 & $36 \cdot 5$ & $34 \cdot 5$ \\
III. & 12 & $15 \cdot 2$ & $11 \cdot 5$ \\
IV. & 90 & $90 \cdot 9$ & $92 \cdot 2$ \\
V. & 75 & $73 \cdot 5$ & $74 \cdot 6$ \\
VI. & 16 & $19 \cdot 3$ & $15 \cdot 8$ \\
VII. & 5 & $8 \cdot 2$ & $3 \cdot 7$ \\
& 20 & $23 \cdot 0$ & $19 \cdot 8$ \\
\hline
\end{tabular}

These results confirm those previously obtained by us and those of Morrell (loc. cit.).

Finally we conclude that-

1. The substances most likely to be used to adulterate turpentine are those which are sold on a large scale as substitutes for it.

2. These are in most cases prepared from such varieties of petroleum as yield, in the fractions which are of suitable volatility, large proportions of aromatic hydrocarbons.

3. Such mixtures of hydrocarbons as are mentioned above are, either alone or in the presence of terpenes, but very slightly affected by sulphuric acid of a strength sufficient to effect the polymerisation of the normal constituents of American turpentine, and that this circumstance affords the best means of their separation* and the estimation of their amount.

4. The admixture of these substances with turpentine has such an effect on its volatility and surface tension as to render the flash-point † (Abel close test) and frothing test the best means of detecting their presence. The latter test also gives

* We note that Richardson and Whitaker fully appreciate the qualitative value of this process.

$\dagger$ The close flash of turpentine substitutes has been found by us to range between $74^{\circ}$ and $104^{\circ} \mathrm{F}$., and therefore a normal "flash" does not necessarily preclude adulteration. 
useful quantitative indications under certain circumstances (Nash, ANALYst, 1909, 34, 151). Fractional distillation should also be carried out.

5. The proportion of aromatic hydrocarbons in mixtures from which terpenes have been removed can be estimated approximately by either a method of nitration, as used by Steuart, Jones, and Wootton and Coste ; or one of sulphonation, as used by Richardson and Whitaker, and suggested also by Coste.

\section{Discussion.}

Mr. Chapman asked if the authors could say what was the general view held by turpentine users as to whether the presence of pine-wood oil-the oil distilled directly from the wood-should be regarded as an adulteration or not.

Mr. Coste said that in the London County Council $v$. Holzapfel it was held that any mixture which contained a substance coming within the definition of petroleum laid down in the Petroleum Acts, and of which the flash-point was below $73^{\circ} \mathrm{F}$., must be regarded as petroleum to which such Acts apply, ${ }^{*}$ so that many of the adulterated samples referred to by Mr. Richardson could not lawfully be stored except under licence from the authority administering the Petroleum Acts, and therefore, as had been indicated in the paper, the conditions with which Mr. Richardson had to deal were somewhat unusual. With regard to the Armstrong process, their point was rather that the turpentine substitutes ordinarily sold at the present time contained large proportions of aromatic hydrocarbons, and that, this being the case, it was injudicious to employ any treatment with sulphuric acid that could cause the sulphonation of such hydrocarbons. Jacobsen and Ivan Levinstein had shown that ordinary concentrated sulphuric acid would dissolve, with sulphonation, both $\mathrm{m}$ - and o-xylene in the cold, and many other hydrocarbons were similarly sulphonated; so that, in using Armstrong's process for the purpose of determining modern turpentine substitutes in turpentine, one must be careful that the chemical processes going on were understood, or one might be sulphonating the hydrocarbons, and possibly forming additive compounds of any olefines that might be present.

Mr. NASH said that he had not found American turpentine coming into this country to be adulterated with pine-wood spirit. This spirit, when properly rectified, yielded an excellent white product, very similar in physical properties to American turpentine, and personally he should be inclined to use it almost as readily as American turpentine. Nevertheless, it was, of course, not turpentine, and if he found American turpentine to contain it he should feel bound to say that it was not pure American turpentine.

Mr. Chapman asked if Mr. Nash had found the Herzfeld test for pine-wood oil to be satisfactory. He (Mr. Chapman) had recently met with some samples, which he believed to be pine-wood oil, which did not give the reaction.

Mr. NASH said that so far as he knew the Herzfeld test was satisfactory. A strong reaction was given by Finnish and Russian turpentine, or by any turpentine distilled from the wood. With regard to Roumanian spirit, he had been informed by

* This decision is adopted by Order in Council of May 7, 1907, whereby the Acts are made to "apply to any mixture of petroleum with any other substance. . "-Statutory Rules and Orders, 1907, No. 483. 
some of the largest suppliers of turpentine substitutes in this country that the spirit they used was Roumanian spirit, the reason being that American petroleum yielded better burning oil than Roumanian, and also that Roumanian oil yielded far more spirit than American. He was surprised to hear from Mr. Richardson that benzene and gasoline were used in the North, because light spirits were much in demand for motors, etc., and the heavier kinds were much more suitable for turpentine substitutes.

Messrs. F. W. Richardson and J. E. F. Whitaker send the following note: We are at a loss to understand the remark that no spirit flashing below $73^{\circ} \mathrm{F}$.hence no gasoline-is used, or that benzol, on account of its inflammability, is likely to be employed for the adulteration of turpentines; but Messrs. Coste and Nash say that they have not met with an adulterated sample of turpentine for some years, and as we have analysed a number of commercially adulterated turpentines we speak from actual experience.

We have analysed several so-called "turpentines" which flashed at the ordinary temperature and which contained gasoline. We only suggest the possibility of the use of benzol on account of its very low price-so low that motorists have turned to it as a cheap substitute for petrol. The adulterator does not concern himself with possible difficulties with insurance companies as long as he sells his material. We do not affirm the possibility of always being able to separate turpentine adulterants by mere fractional distillation. By using Young's still head we can absolutely separate gasoline and also benzol with fair accuracy from turpentine which has a much higher distilling temperature. In the absence of Borneo spirit and Roumanian spirit, hitherto not found by us in use as turpentine substitutes-an absence proved by the low barium sulphate coefficient-we do maintain that the Richardson and Bowen method of calculation, using the refractive indices of the fractional distillates, gives good results. American petroleum products are used in quite overwhelming proportion to any others for turpentine adulteration. In certain cases it would no doubt be advisable to classify the constituents of a mixture as described by Messrs. Coste and Nash; but most of the adulterated samples we have examined have allowed of a more popular grouping, "gasoline" and "petroleum" representing paraffins coming over on distillation at well-defined temperatures, the amounts being calculated from the data given by the distillates.

The term "cyclo-paraffins" might be very confusing to the non-chemical mind. The authors agree with us that "distillation of the sample will also give valuable information."

The Richardson-Whitaker methods allow the analyst to make a classification of the constituents of an adulterated turpentine in such a manner as to give a good general idea of the nature and amounts of the adulterants-not merely a division into turpentines and paraffins.

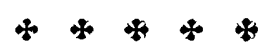

